\title{
Chromosomal $\beta$-lactamase expression and antibiotic resistance in Enterobacter cloacae
}

\author{
YOUJUN YANG, D. M. LIVERMORE and ROSAMUND J. WILLIAMS
}

Department of Medical Microbiology, London Hospital Medical College, Turner Street, London E1 2AD

\begin{abstract}
Summary. The activities of $\beta$-lactam antibiotics were compared against Enterobacter cloacae clinical isolates and mutants which had inducible, stably-derepressed, and basal expression of a $p \mathrm{I} 8.4$ subtype of the Ia chromosomal $\beta$-lactamase. These activities were correlated with the results of studies of the $\beta$-lactamase-lability and $\beta$ lactamase-inducer-power of the antibiotics. Cefoxitin and ampicillin were labile, and induced $\beta$-lactamase production strongly at concentrations below their MIC values. Consequently, $\beta$-lactamase-inducible and $\beta$-lactamase-stably-derepressed organisms were highly resistant (MIC $>256 \mathrm{mg} / \mathrm{L}$ ) to these antibiotics, whereas enzyme-basal strains and mutants were much more susceptible (MIC $1-16 \mathrm{mg} / \mathrm{L}$ ). Imipenem also induced $\beta$-lactamase production strongly at concentrations below its MIC, but was more stable than ampicillin and cefoxitin. It was active against enzyme-inducible and stably-derepressed organisms at $0.25-0.5 \mathrm{mg} / \mathrm{L}$ and against $\beta$-lactamase-basal organisms at $0.06-0.25 \mathrm{mg} / \mathrm{L}$. Thus the $\beta$-lactamase afforded only very low-level protection against imipenem; this appeared to be by a non-hydrolytic mechanism, with the enzyme binding to the antibiotic in a relatively stable complex. This complex, which probably was an intermediate in a hydrolytic pathway, was isolated by gelfiltration chromatography and shown to have a breakdown half-life of $47 \pm 2 \mathrm{~min}$. Cefotaxime, ceftriaxone and mezlocillin were labile to the $p$ I 8.4 $\beta$-lactamase but induced $\beta$-lactamase production weakly at concentrations below their MIC values. Consequently, $\beta$-lactamase-inducible and $\beta$-lactamase-basal organisms remained equally susceptible (MIC $0.06-4 \mathrm{mg} / \mathrm{L}$ ), but stably-derepressed organisms were considerably more resistant $(\mathrm{MIC}>64 \mathrm{mg} / \mathrm{L})$ to these antibiotics.
\end{abstract}

\section{Introduction}

Strains of Enterobacter cloacae almost invariably produce a chromosomally-mediated $\beta$-lactamase, which has been designated 'Ia enzyme' by Richmond and Sykes (1973). About $80 \%$ of clinical isolates have inducible expression of this $\beta$-lactamase. A minority of isolates have stably-derepressed or basal expression of the Ia enzyme. Stably-derepressed organisms produce large amounts of $\beta$-lactamase without induction; basal organisms produce minimal amounts of the enzyme regardless of the presence of inducers. Stablyderepressed mutants tend to segregate from inducible strains at high frequency (Wiedemann, 1986).

In general, $\beta$-lactamase-inducible $E$. cloacae strains are susceptible to third-generation cephalo-

Received 9 April 1987; accepted 16 June 1987. sporins and imipenem, but resistant to ampicillin and cefoxitin. Ureidopenicillins and carboxypenicillins are active against those $\beta$-lactamase-inducible isolates that lack plasmid-mediated $\beta$ lactamases such as TEM-1 enzyme. Stably-derepressed organisms are resistant to virtually all $\beta$ lactams, except imipenem and temocillin, and pose an increasing clinical problem (Sanders, 1983; Sanders and Sanders, 1985). $\beta$-Lactamase-basal strains are susceptible to most $\beta$-lactams, often including cefoxitin and ampicillin. Similar relationships between $\beta$-lactamase expression and antibiogram have been reported in laboratory mutants of E. cloacae (Curtis et al., 1986).

In the present study we attempted to correlate antibiogram data for various inducibility types of $E$. cloacae with direct measurements of the $\beta$ lactamase-lability and inducer power of a range of newer $\beta$-lactam antibiotics. 


\section{Materials and methods}

\section{E. cloacae strains}

$\beta$-Lactamase-inducible, $\beta$-lactamase-stably-derepressed and $\beta$-lactamase-basal strains were selected from a collection of $48 \mathrm{E}$. cloacae strains isolated from patients at the London Hospital during 1982-1983. Identification was by the API 20E system. Details of the selected organisms, and of mutants derived from them, are given in table I. Stably-derepressed mutants were selected from inducible strains by spreading c. $5 \times 10^{8} \mathrm{cfu}$, from overnight cultures in Nutrient Broth No. 2 (Oxoid) on Diagnostic Sensitivity Test Agar (DST; Oxoid) containing cefotaxime $50 \mathrm{mg} / \mathrm{L}$. The colonies that grew on this medium after overnight incubation at $37^{\circ} \mathrm{C}$ were subcultured on antibiotic-free DST agar, and then characterised. $\beta$-Lactamase-basal mutants were derived from stablyderepressed organisms by mutagenesis with $\mathrm{N}$-methyl$\mathrm{N}^{\prime}$-nitro-N-nitrosoguanidine (Curtis et al., 1978).

\section{Antibiotics}

Antibiotics were obtained as dry powders from suppliers as follows: ampicillin sodium and carbenicillin disodium from Beecham Research Laboratories, Brockham Park, Surrey; mezlocillin from Bayer Pharmaceuticals UK, Haywards Heath, Sussex; benzylpenicillin, cephaloridine and nitrocefin from Glaxo Group Research, Greenford, Middlesex ; cefotaxime from HoechstRoussell, Somerville, NJ, USA; cefoxitin and imipenem from Merck, Sharp and Dohme Ltd, Hoddesdon, Herts, UK; ceftriaxone from Roche Products Ltd, Welwyn Garden City, Herts, UK; and cephalothin from the Sigma Chemical Co., St Louis, MO, USA.

\section{Susceptibility tests}

Minimum inhibitory concentrations (MICs) of antibiotics were measured in agar, with an inoculum of $10^{4}$ cfu in $0.001 \mathrm{ml}$, taken from an overnight nutrient-broth culture.

\section{$\beta$-Lactamase induction assays}

The organisms were seeded into $10-\mathrm{ml}$ volumes of Isosensitest Broth (Oxoid). After overnight incubation at $37^{\circ} \mathrm{C}$, with continuous agitation, $1-\mathrm{ml}$ volumes of these cultures were subcultured into pre-warmed 9-ml amounts of the same medium. Incubation was continued and inducers were added $90 \mathrm{~min}$ after subculture; $4 \mathrm{~h}$ after the addition of the inducers the cells were harvested by centrifugation at $5000 \mathrm{~g}$ and $37^{\circ} \mathrm{C}$, then sonicated on ice. The $\beta$-lactamase activity of the sonicates was measured by spectrophotometric assay at $295 \mathrm{~nm}$ with $10 \mathrm{mM}$ cephaloridine as the substrate in $0.1 \mathrm{M}$ phosphate buffer, $p \mathrm{H} \mathrm{7.0.} \mathrm{The} \mathrm{assay} \mathrm{temperature} \mathrm{was} 37^{\circ} \mathrm{C}$, and the lightpath was $1 \mathrm{~mm}$. Enzyme yields were standardised against protein concentration, which was estimated by the method of Lowry et al. (1951) with bovine serum albumin as the reference standard.

\section{$\beta$-Lactamase extraction}

Cultures were grown overnight in Isosensitest Broth at $37^{\circ} \mathrm{C}$, with continuous agitation, then diluted 10 -fold into fresh identical broth, previously warmed to $37^{\circ} \mathrm{C}$. Incubation was continued for $4 \mathrm{~h}$, in the same conditions. Subsequently, the cells were harvested by centrifugation for $15 \mathrm{~min}$ at $5000 \mathrm{~g}$ and $37^{\circ} \mathrm{C}$, washed once in $0.1 \mathrm{M}$

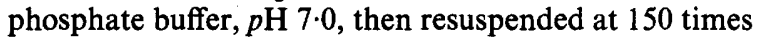
their original density in $0 \cdot 1 \mathrm{M}$ phosphate buffer, $p \mathrm{H} 7 \cdot 0$. $\beta$-Lactamase was released by subjecting the cell suspension to four cycles of alternate freezing and thawing. Debris was removed by centrifugation for $30 \mathrm{~min}$ at $100000 \mathrm{~g}$ and $4^{\circ} \mathrm{C}$, and the $\beta$-lactamase-containing supernates were stored at $-20^{\circ} \mathrm{C}$.

The $\beta$-lactamase extracted from $4 \mathrm{~L}$ of culture of $E$. cloacae strain 100 by this procedure was purified to

Table I. E. cloacae wild types and mutants and their $\beta$-lactamase production characteristics

\begin{tabular}{|c|c|c|c|c|c|}
\hline \multirow[b]{2}{*}{ Strain } & \multirow[b]{2}{*}{ Derivation } & \multirow[b]{2}{*}{$\begin{array}{l}\beta \text {-lactamase } \\
\text { inducibility }\end{array}$} & \multicolumn{3}{|c|}{ Activity against cephaloridine $†$} \\
\hline & & & not induced & $\begin{array}{c}\text { induced with } \\
\text { imipenem }(1 \mathrm{mg} / \mathrm{L})\end{array}$ & $\begin{array}{c}\text { induced with } \\
\text { cefoxitin }(100 \mathrm{mg} / \mathrm{L})\end{array}$ \\
\hline 100 & Clinical isolate & SDR & 31800 & 20100 & 32800 \\
\hline 100 -def & NTG mutant of 100 & B & $22 \cdot 1$ & $25 \cdot 8$ & 56.8 \\
\hline 84 & Clinical isolate & SDR & 16100 & 38200 & 40600 \\
\hline 84-def & NTG mutant of 84 & B & $56 \cdot 8$ & 497 & 345 \\
\hline $684-I$ & Clinical isolate & I & $45 \cdot 8$ & 20700 & 5800 \\
\hline 684-con & Cefotaxime-selected mutant of 684I & B & 25100 & 34900 & 44700 \\
\hline 684-def & NTG mutant of 684-con & B & $42 \cdot 2$ & $40 \cdot 8$ & $43 \cdot 2$ \\
\hline 144 & Clinical isolate & $\mathbf{B}$ & $62 \cdot 2$ & 101 & 72 \\
\hline 158 & Clinical isolate & B & $9 \cdot 10$ & $14 \cdot 4$ & $7 \cdot 2$ \\
\hline
\end{tabular}

$\mathrm{B}=$ basal $; \mathrm{I}=$ inducible $; \mathrm{SDR}=$ stably derepressed $; \mathrm{NTG}=\mathrm{N}$-methyl N'-nitro-N-nitrosoguanidine.

$\uparrow$ Drug hydrolysed: $\mathrm{nmol} / \mathrm{min} / \mathrm{mg}$ of protein. 
homogeneity by a two-step ion-exchange procedure (Livermore et al., 1986). The mol. wt and purity of the enzyme were examined by SDS-PAGE, as described previously (Livermore et al., 1986).

\section{Hydrolysis and inhibition assays}

Hydrolysis of $\beta$-lactams by crude and purified $\beta$ lactamase preparations was examined by UV spectrophotometric assay (O'Callaghan et al., 1969; Waley, 1974). The antibiotic solutions were prepared in $0.1 \mathrm{M}$ phosphate

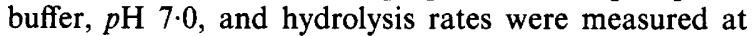
$37^{\circ} \mathrm{C}$. The light path normally was $1 \mathrm{~cm}$, but $1 \mathrm{~mm}$ lightpath cuvettes were used for assays with high substrate concentrations $(>1 \mathrm{mM})$. The assay wavelengths selected for the antibiotics were as follows: ampicillin, benzylpenicillin, carbenicillin and mezlocillin $235 \mathrm{~nm}$; cefotaxime $255 \mathrm{~nm}$; ceftriaxone $257 \mathrm{~nm}$; cefoxitin $260 \mathrm{~nm}$; cephaloridine $255 \mathrm{~nm}$ and $295 \mathrm{~nm}$; cephalothin $287 \mathrm{~nm}$; and imipenem $297 \mathrm{~nm}$. Kinetic parameters $\left(V_{\text {max }}, k_{\text {cat }}\right.$ and $K_{\mathrm{m}}$ ) were derived by linear regression analysis of Hanes $(S / V$ vs $S)$ plots of initial velocity $(V)$ data obtained at 810 different substrate $(S)$ concentrations.

Imipenem was tested as an inhibitor of cephaloridine hydrolysis under the following conditions: (i) where $1 \mathrm{mM}$ cephaloridine and 0.1-200 nM imipenem were mixed in

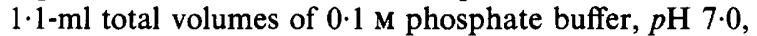
and the reaction was started by addition of enzyme $(25 \mu \mathrm{l})$; or (ii) where $0.01-20 \mathrm{~nm}$ imipenem and enzyme were incubated together at $37^{\circ} \mathrm{C}$ for $15 \mathrm{~min}$ in $1.025 \mathrm{ml}$

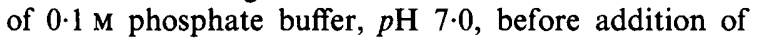
$100 \mu$ of $10 \mathrm{~mm}$ cephaloridine.

To isolate imipenem-inactivated $\beta$-lactamase, a mixture of imipenem $(11.1 \mu \mathrm{mol})$ and enzyme $(1.1 \mathrm{nmol})$ was

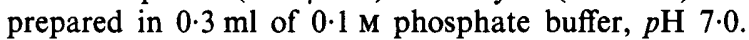
After incubation for $15 \mathrm{~min}$ at $37^{\circ} \mathrm{C}$ the mixture was chromatographed at $4^{\circ} \mathrm{C}$ on a $30 \times 0.9-\mathrm{cm}$ column of Sephadex G25, which had previously been equilibrated in $0.1 \mathrm{M}$ phosphate buffer, $p \mathrm{H} \mathrm{7.0.} \mathrm{Elution} \mathrm{was} \mathrm{with} \mathrm{the}$ same buffer at a flow rate of $0.25 \mathrm{ml} / \mathrm{min}$ and the time required for elution was determined during preliminary experiments with imipenem-untreated enzyme. The enzyme-containing fractions were collected, pooled, and warmed to $37^{\circ} \mathrm{C}$. Samples were withdrawn periodically and their $\beta$-lactamase activity was compared to that of column-passaged imipenem-untreated enzyme, with $1 \mathrm{mM}$ cephaloridine as the substrate.

\section{Results}

\section{$\beta$-Lactamase production by $E$. cloacae wild type and mutant strains}

Isoelectric focusing revealed that most (36 out of 48 ) of the E. cloacae isolates from clinical specimens produced a form of Ia $\beta$-lactamase that focused at pI 8.4. Relative hydrolysis rates of $1 \mathrm{~mm}$ cephaloridine, $1 \mathrm{~mm}$ cephalothin and $1 \mathrm{~mm}$ benzylpenicillin by this $\beta$-lactamase were in the approximate ratios $100: 57: 3$, regardless of the strain used as a source of enzyme.

Strains with inducible, stably-derepressed and basal $p$ I 844-enzyme expression were selected for detailed study, and quantitative induction data for these organisms, and their laboratory-derived mutants, are given in table I. Strain 684I had inducible expression of the enzyme, but derepressed mutants segregated at an approximate frequency of $10^{-8}$. Wild-type strains 84 and 100 , and the laboratoryderived mutant 684-con, constitutively produced large amounts of the $\beta$-lactamase, whereas the basal mutants 684-def and 100-def and the isolates 144 and 158 had only trace amounts of the enzyme. Mutant 84-def produced more $\beta$-lactamase than the other $\beta$-lactamase-basal organisms, but much less than its stably-derepressed parent strain, 84 .

None of the strains studied in detail produced plasmid-mediated-type $\beta$-lactamases. Such enzymes, however, were present in 20 of the 48 clinical isolates.

\section{Antibiotic susceptibility}

The $\beta$-lactamase-inducible strain 684I was very susceptible $(\mathrm{MIC}<4 \mathrm{mg} / \mathrm{L})$ to all the $\beta$-lactams tested except ampicillin and cefoxitin (table II). Its stably-derepressed mutant, 684-con, was highly resistant $(\mathrm{MIC}>128 \mathrm{mg} / \mathrm{L})$ to all the $\beta$-lactams except imipenem, as were the stably-derepressed clinical isolates 84 and 100. Strains 684I and 684con were both equally susceptible to imipenem $(\mathrm{MIC}=0.25 \mathrm{mg} / \mathrm{L})$.

The $\beta$-lactamase-basal isolates 144 and 158 , and laboratory mutants 100 -def and 684-def, were susceptible to $16 \mathrm{mg} / \mathrm{L}$ or less of all the $\beta$-lactams tested, including ampicillin and cefoxitin. Mutant 84-def, which produced larger amounts of Ia enzyme than the other basal mutants, remained resistant to ampicillin and cefoxitin (MIC 64$512 \mathrm{mg} / \mathrm{L}$ ) and was only moderately susceptible to third-generation cephalosporins and mezlocillin (MICs 8-16 mg/L).

Mutant 684-def was only 2-4-fold more susceptible than strain $684 \mathrm{I}$ to third-generation cephalosporins, mezlocillin and carbenicillin, but was fourfold more susceptible to imipenem and $>128$-fold more susceptible to ampicillin and cefoxitin.

MICs of non- $\beta$-lactam antibiotics (gentamicin, chloramphenicol, tetracycline and nalidixic acid) remained constant within each mutant series (data not shown), suggesting that permeability changes had not arisen simultaneously with altered $\beta$ lactamase synthesis. 
Table II. Susceptibility of $E$. cloacae wild type and mutant strains to $\beta$-lactam antibiotics

\begin{tabular}{|c|c|c|c|c|c|c|c|}
\hline \multirow[b]{2}{*}{ Strain } & \multicolumn{7}{|c|}{$\mathrm{MIC}(\mathrm{mg} / \mathrm{L})$} \\
\hline & ampicillin & carbenicillin & mezlocillin & cefotaxime & ceftriaxone & cefoxitin & imipenem \\
\hline 100 & 2084 & 64 & 128 & 512 & 512 & 1024 & $0 \cdot 5$ \\
\hline 100 -def & 4 & 16 & 2 & 0.12 & 0.12 & 4 & 0.06 \\
\hline 84 & $>2048$ & 128 & 128 & 256 & 512 & 256 & 1 \\
\hline 84-def & 512 & 16 & 8 & 8 & 16 & 64 & 0.25 \\
\hline $684 \mathrm{I}$ & 512 & 4 & 4 & 0.5 & $0 \cdot 25$ & 256 & $0 \cdot 25$ \\
\hline 684-con & 2048 & 256 & 128 & 256 & 256 & 512 & $0 \cdot 25$ \\
\hline 684-def & 4 & 2 & 1 & 0.06 & 0.06 & 2 & 0.06 \\
\hline 144 & 16 & 2 & 2 & 0.25 & $0 \cdot 5$ & 8 & 0.25 \\
\hline 158 & 1 & 2 & 2 & 0.015 & $0 \cdot 12$ & 4 & $0 \cdot 25$ \\
\hline
\end{tabular}

\section{Inducer power of $\beta$ lactams}

The inducer power of $\beta$-lactams was examined for strain 684I, and the results are summarised in fig. 1. Imipenem appeared to be the strongest inducer at low concentrations, giving 200-300-fold induction when used below $1 \mathrm{mg} / \mathrm{L}$. Cefoxitin also was a strong inducer, giving 100 -fold induction at $10 \mathrm{mg} / \mathrm{L}$. The other $\beta$-lactams were very poor inducers below $10 \mathrm{mg} / \mathrm{L}$, but caused up to 40 -fold induction at $100 \mathrm{mg} / \mathrm{L}$.

The values of induction ratios should be taken as only semi-quantitative because their calculation is subject to several distortions. In particular, (i) the assays measured only cell-bound $\beta$-lactamase and significant enzyme leakage may have occurred, especially from cells exposed to supra-MIC antibiotic concentrations, (ii) the induction is time dependent and the choice of induction period was arbitrary and (iii) residual inducer may interfere with $\beta$-lactamase assay. Nonetheless there was a dramatic difference between imipenem and cefoxitin, which induced strongly below its MIC value, and cefotaxime, ceftriaxone, mezlocillin and carbenicillin which failed to do so.

\section{$H y d r o l y s i s$ of $\beta$-lactams by $\beta$-lactamase from $E$. cloacae strain 100}

E. cloacae strain 100 was selected as a source of the $p$ I 8.4 enzyme for detailed hydrolysis studies. The enzyme preparation purified from this organism contained a single protein species, which had a mol. wt of 46000 , as measured by SDS-PAGE. Kinetic parameters for the hydrolysis of $\beta$-lactams by this enzyme are listed in table III. The $k_{\text {cat }}$ value (molecules of antibiotic hydrolysed per molecule of enzyme per unit time) for cephaloridine was 45 times that for benzylpenicillin; however the $K_{\mathrm{m}}$ of

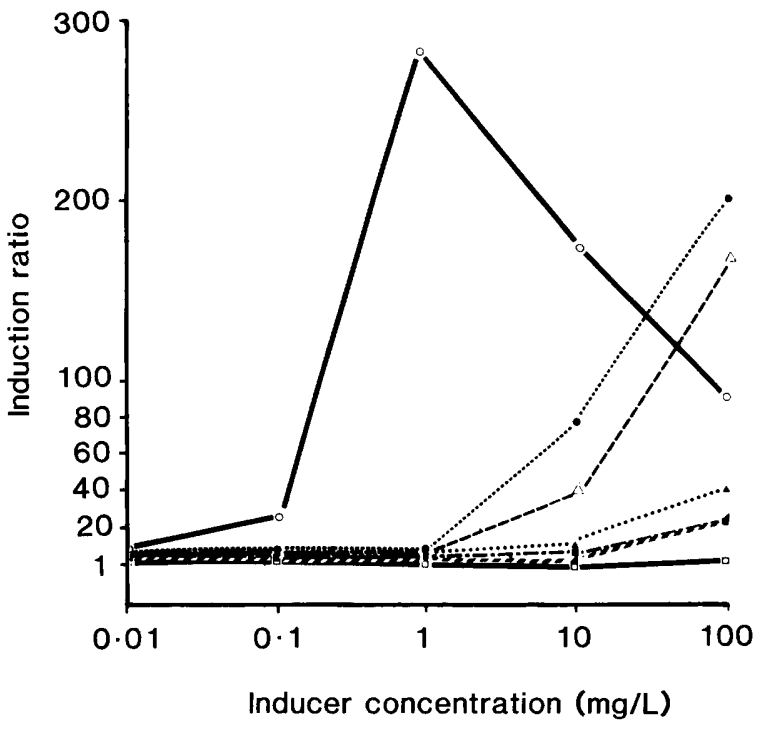

Fig. 1. $\beta$-Lactamase induction in $E$. cloacae strain $684 \mathrm{I}$ by imipenem $\bigcirc-O$, cefoxitin...-- , cefotaxime $\triangle--\triangle \triangle$, ceftriaxone $\boldsymbol{\Delta} \ldots . . . . \Delta$, carbenicillin $\boldsymbol{\Delta}-. . . . \Delta$, ampicillin ( Induction ratios were calculated as the enzyme quantity/mg of cell protein in the presence of inducer, divided by enzyme quantity/mg of cell protein in the absence of inducer.

cephaloridine $(610 \mu \mathrm{M})$ was much higher than that of benzylpenicillin $(10 \mu \mathrm{M})$, with the result that $k_{\text {cat }} /$ $K_{\mathrm{m}}$ ratios were similar for the two antibiotics. For cefoxitin and ceftriaxone, $k_{\text {cat }}$ values were in the range $0 \cdot 2-1 / \mathrm{min}$; those for ampicillin, carbenicillin, mezlocillin and cefotaxime were in the range 5-40/ min. $K_{\mathrm{m}}$ values for carbenicillin, cefoxitin and ceftriaxone were below $2 \mu \mathrm{M}$; those for ampicillin, mezlocillin and cefotaxime were in the range 5$44 \mu \mathrm{M}$. We did not observe non-Michaelis-Menten hydrolysis kinetics for any of the agents tested, 
despite using antibiotic concentrations as low as $1 \cdot 25 \mu \mathrm{M}$.

Hydrolysis of imipenem was too slow to be measured accurately; however, the compound did inhibit the enzyme, and the kinetics of this behaviour were investigated. The $I_{50}$ concentration of imipenem for inhibition of the hydrolysis of $1 \mathrm{~mm}$ cephaloridine was $0 \cdot 19 \mu \mathrm{M}$ when the enzyme and imipenem were not pre-incubated, but was decreased to $0.04 \mu \mathrm{M}$ when the enzyme and imipenem were incubated together for $15 \mathrm{~min}$ at $37^{\circ} \mathrm{C}$ before adding of cephaloridine. These results suggested the accumulation of an enzyme-imipenem complex during the pre-incubation period, and isolation of this complex by gel-filtration chromatography was undertaken. The conditions were such that free, or imipenem-inactivated, $\beta$ lactamase eluted with the void volume of the column, about $30 \mathrm{~min}$ after loading, and was separated completely from unbound imipenem, which was retained in the gel matrix for $4-5 \mathrm{~h}$. Immediately after elution, the imipenem-treated enzyme lacked catalytic activity against $1 \mathrm{~mm}$ cephaloridine. However, the enzyme activity recovered progressively when the complex was incubated at $37^{\circ} \mathrm{C}$. This recovery obeyed first-order kinetics, such that a plot of log percentage inactivation of the enzyme versus time was linear (fig. 2). The half-life of the inactivated species was about $47 \pm 2 \mathrm{~min}$.

\section{Discussion}

Hyperproduction of Ia $\beta$-lactamase by $E$. cloacae has been associated with the development of resistance to most new $\beta$-lactams except imipenem (Sanders and Sanders, 1985). Hyperproduction

Table III. Kinetics of hydrolysis of $\beta$-lactams by $p \mathrm{I} 8 \cdot 4$ $\beta$ lactamase from $E$. cloacae strain 100

\begin{tabular}{lccc}
\hline Antibiotic & $k_{\mathrm{cat}}\left(\mathrm{min}^{-1}\right)^{*}$ & $K_{\mathrm{m}}(\mu \mathrm{M})$ & $\begin{array}{c}k_{\mathrm{cat}} / K_{\mathrm{m}} \\
\left(\mathrm{min}^{-1} \mu \mathrm{M}^{-1}\right)\end{array}$ \\
\hline Benzylpenicillin & 488 & 10 & 48.8 \\
Cephaloridine & 22000 & 610 & 36.1 \\
Cefotaxime & 40 & 44 & 0.91 \\
Ceftriaxone & 0.82 & 1 & 0.82 \\
Cefoxitin & 0.24 & 1.5 & 0.16 \\
Ampicillin & 55 & 4 & 13.75 \\
Carbenicillin & 5.24 & 0.15 & 34.9 \\
Mezlocillin & 9.81 & 5.5 & 1.98
\end{tabular}

* Maximum number of antibiotic molecules hydrolysed per minute by one enzyme molecule.

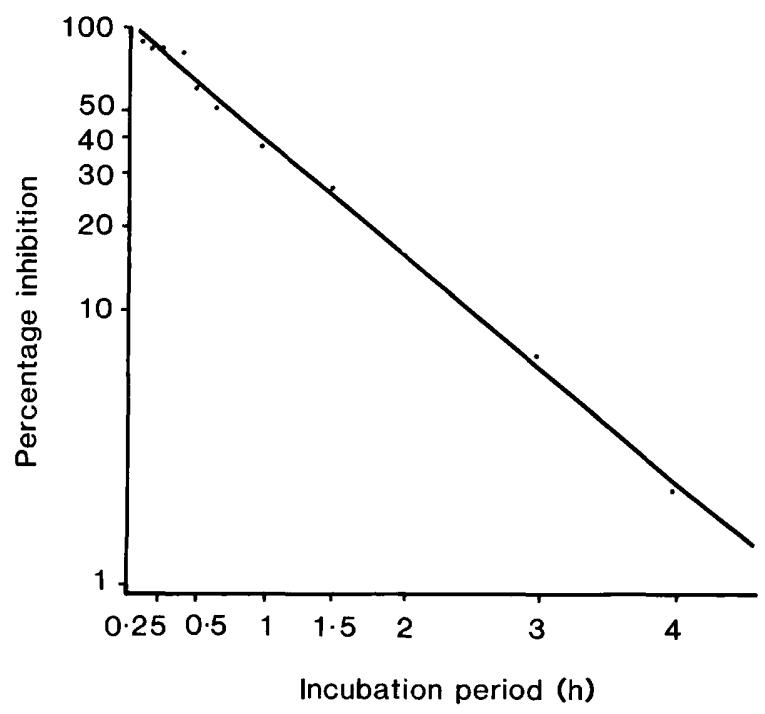

Fig. 2. Recovery of cephaloridine-hydrolysing activity by the isolated $p$ I 8.4 enzyme-imipenem complex. The complex was incubated at $37^{\circ} \mathrm{C}$ and samples were periodically withdrawn and tested (see Methods). Percentage inactivation was calculated as $\left[\left(A_{0}-A\right) / A_{0}\right] \times 100$ where $A_{0}$ was the activity of columnpassaged, imipenem-untreated-enzyme and $A$ was the activity of column-passaged imipenem-treated enzyme.

arises transiently in inducible strains during exposure to strong inducers, and permanently in stablyderepressed mutants, which have an altered $\beta$ lactamase-regulatory gene (Lindberg and Normark, 1986). Stably-derepressed mutants are segregated by inducible populations at high frequency $\left(10^{-5}-10^{-8}\right)$ and may be selected during clinical exposure to $\beta$-lactams (Sanders, 1983). Similar induction and selection phenomena are observed in other Class I $\beta$-lactamase-inducible species, such as Pseudomonas aeruginosa, Citrobacter spp., Serratia spp. and the indole-positive Proteus spp. (Sanders and Sanders, 1985; Livermore, in press). In this study we attempted to relate MIC data for $\beta$ lactamase inducible, stably-derepressed and basal E. cloacae isolates and mutants to direct measurement of the $\beta$-lactamase lability and inducer power of various $\beta$-lactams. All the strains examined produced a $p$ I 8.4 form of the Ia enzyme, which we have found to be the commonest subtype of Ia enzyme in $E$. cloacae isolated at the London Hospital.

MICs of all the $\beta$-lactams for the stably-derepressed strains and mutants exceeded those for the basal strains and mutants, indicating that hyperproduction of the $p \mathrm{I} 8.4$ enzyme was protective against all these agents including imipenem. However, the protection against imipenem was much 
less than against the penicillins and cephalosporins that we tested. The MICs of imipenem for the derepressed isolates and mutants, unlike those of other $\beta$-lactams, remained in the therapeutic range.

For all the compounds except imipenem, the protection afforded to the derepressed organisms by the $p \mathrm{I} 8.4 \beta$-lactamase could be correlated with the hydrolytic activity of this enzyme. Although the $k_{\text {cat }}$ values of the enzyme for cefoxitin, ceftriaxone, mezlocillin and carbenicillin were $<0.1 \% k_{\text {cat }}$ cephaloridine, suggesting high stability, the $K_{\mathrm{m}}$ values of these antibiotics also were low, giving high $k_{\text {cat }} / K_{\mathrm{m}}$ ratios. As has been discussed elsewhere, the magnitude of the $k_{\text {cat }} / K_{\mathrm{m}}$ ratio, $\left(=V_{\max } /\right.$ $K_{\mathrm{m}}$ divided by enzyme quantity) is the critical determinant of the hydrolytic efficiency of a $\beta$ lactamase against the low antibiotic concentrations that may be attainable in the bacterial cell (Livermore, 1983, 1985; Vu and Nikaido, 1985; Bush and Sykes, 1986). A high $k_{\text {cat }} / K_{\mathrm{m}}$ ratio suggests that the enzyme may be efficient against the antibiotic inside the cell. Unlike the other compounds tested, imipenem was not hydrolysed at a significant rate by the $p$ I $8.4 \beta$-lactamase; however, it did inhibit the activity of this enzyme against cephaloridine. The inhibition was increased when imipenem and enzyme were pre-incubated before addition of the substrate, suggesting the accumulation of an inert imipenem- $\beta$-lactamase complex. Gel filtration allowed the isolation of this complex, which was found to have a breakdown half-life of $47 \pm 2 \mathrm{~min}$. Since this half-life exceeds the generation time for exponentially growing $E$. cloacae $(c .20 \mathrm{~min})$ it seems likely that the feeble protection that the $\beta$ lactamase provided against imipenem depended, at least partly, on a non-hydrolytic mechanism, with the enzyme trapping the imipenem molecules. We have no direct data on the chemical nature of the imipenem-Ia enzyme complex; however, similarly stable Class I $\beta$-lactamase-antibiotic complexes commonly contain a covalent acyl link between the enzyme and the $\beta$-lactam and are normal intermediates on a hydrolytic pathway (Bush et al., 1982). Theoretical considerations suggest that such covalent trapping is a credible cause of $\beta$-lactamase mediated resistance (Livermore, 1987) whereas the non-covalent trapping suggested previously remains arguable (Livermore, 1985, 1987).

Inducible expression of the $p$ I 8.4 enzyme conferred narrower-spectrum resistance than did stable derepression. Thus, although MICs of imipenem, ampicillin and cefoxitin for strain 684I were similar to those for 684-con, those of cefotaxime, ceftriaxone, mezlocillin and carbenicillin remained almost as low as for 684-def and the other $\beta$-lactamase-basal organisms. We could relate these findings to the direct observation that the cephalosporins, mezlocillin and carbenicillin were very weak $\beta$-lactamase inducers at low concentrations (fig. 1). Thus, although labile, it seems that these compounds inhibit growth at concentrations below those required to induce protective quantities of the $p \mathrm{I} 8 \cdot 4 \beta$-lactamase in inducible strains such as 684I. Conversely imipenem, cefoxitin and, to a lesser extent, ampicillin were strong inducers below their MIC values, with the result that inducible $\beta$ lactamase expression was almost as protective as stably-derepressed expression.

The combination of lability with weak inducer power explains the tendency for cephalosporins and ureidopenicillins to select stably-derepressed mutants from $\beta$-lactamase-inducible $E$. cloacae populations. Numerous cases have been reported where selection of this type has occurred in patients receiving therapy with labile weak inducers (Sanders and Sanders, 1985; Livermore, 1986, and in press). Selection of derepressed mutants seems unlikely with imipenem, since it has equal activity against $\beta$-lactamase inducible and stably-derepressed organisms (table II, also Goering et al., 1982). This prediction is supported by the results of Kirkpatrick et al. (1986), who were unable to select $\beta$-lactamase-derepressed $E$. cloacae with imipenem.

The present results for $E$. cloacae broadly resemble previous data for $P$. aeruginosa (Livermore, 1986; Livermore and Yang, 1987). Cefotaxime, ceftriaxone and ureidopenicillins were labile weak inducers for the Class I enzymes of both species, whereas imipenem was a strong inducer that retained activity against inducible and stablyderepressed organisms, despite marginal $\beta$-lactamase lability. However the behaviour of carbenicillin differed markedly between the two species: for $E$. cloacae carbenicillin was a labile weak inducer, behaving similarly to mezlocillin, whereas it is stable to the $P$. aeruginosa enzyme and retained almost equal activity against $\beta$-lactamase-inducible, $\beta$-lactamase-stably-derepressed and $\beta$-lactamase basal organisms (Livermore and Yang, 1987).

Several minor differences were apparent between the $p$ I 8.4 sub-type $E$. cloacae Ia enzyme, studied here, and the more widely-studied, but rarer, P99 sub-type. In particular, the $p$ I 8.4 enzyme exhibited moderate $k_{\text {cat }}(40 / \mathrm{min})$ and $K_{\mathrm{m}}(40 \mu \mathrm{M})$ values for cefotaxime, whereas $k_{\text {cat }}$ and $K_{\mathrm{m}}$ of this drug for P99 enzyme are about $1 / \mathrm{min}$ and $1 \mu \mathrm{M}$ respectively (Bush et al., 1982; Livermore et al., 1986). The $p \mathrm{I}$ 8.4 enzyme also differed from the E-2 form of Ia enzyme described by Seeberg et al. (1983) and Bush 
et al. (1985), both in its kinetics of activity against cefotaxime, wherein E-2 resembled P99 enzyme, and in the stability of its imipenem complex. Bush et al. (1985) reported a half-life of only $0.8 \mathrm{~min}$ for the E-2 enzyme-imipenem complex; considerably less than that observed here for the $p \mathrm{I} 8.4$ enzyme. However, this diversity of Ia $\beta$-lactamase types in

\section{REFERENCES}

Bush K, Freudenberger J S, Sykes R B 1982 Interaction of azthreonam and related monobactams with $\beta$-lactamases from gram-negative bacteria. Antimicrobial Agents and Chemotherapy 22:414-420.

Bush K, Tanaka S K, Bonner D P, Sykes R B 1985 Resistance caused by decreased penetration of $\beta$-lactam antibiotics into Enterobacter cloacae. Antimicrobial Agents and Chemotherapy 27 : $555-560$.

Bush K, Sykes R B 1986 Methodology for the study of $\beta$ lactamases. Antimicrobial Agents and Chemotherapy 30:610.

Curtis N A C, Brown C, Boxall M, Boulton M G 1978 Modified peptidoglycan transpeptidase activity in a carbenicillinresistant mutant of Pseudomonas aeruginosa 18s. Antimicrobial Agents and Chemotherapy 14:246-251.

Curtis N A C, Eisenstadt R L, Rudd C, White A J 1986 Inducible Type I $\beta$-lactamases of Gram-negative bacteria and resistance to $\beta$-lactam antibiotics. Journal of Antimicrobial Chemotherapy 17:51-61.

Goering R V, Sanders C C, Saunders W E 1982 Antagonism of carbenicillin and cefamandole by cefoxitin in treatment of experimental infections in mice. Antimicrobial Agents and Chemotherapy 21:963-967.

Kirkpatrick B, Ashby J, Wise R $1986 \beta$-lactams and imipenem. Lancet i: 802 .

Lindberg F, Normark S 1986 Contribution of chromosomal $\beta$ lactamases to $\beta$-lactam resistance in enterobacteria. Reviews of Infectious Diseases 8 Suppl: S292-S304.

Livermore D M 1983 Kinetics and significance of the activity of the Sabath and Abrahams' $\beta$-lactamase of Pseudomonas aeruginosa against cefotaxime and cefsulodin. Journal of Antimicrobial Chemotherapy $11: 169-179$.

Livermore D M 1985 Do $\beta$-lactamases 'trap' cephalosporins? Journal of Antimicrobial Chemotherapy 15 : 511-514.

Livermore D M 1986 Class I $\beta$-lactamase expression in Pseudomonas aeruginosa and cephalosporin resistance. Lancet i: 450 .

Livermore D M, Riddle S J, Davy K W M 1986 Hydrolytic model for cefotaxime and ceftriaxone resistance in $\beta$ lactamase-derepressed Enterobacter cloacae. Journal of Infectious Diseases 153:619-622.
E. cloacae seems largely of academic interest since the stably-derepressed strains are reported to show a similar spectrum of resistance, irrespective of the enzyme-sub-type that they produce.

We are grateful to Merck, Sharp and Dohme (UK) for support.

Livermore D M Clinical signficance of beta-lactamases induction and stable derepression in Gram-negative rods. European Journal of Clinical Microbiology (in press).

Livermore D M 1987 "Covalent trapping" and latamoxefresistance in $\beta$-lactamase-derepressed Pseudomonas aeruginosa. Journal of Antimicrobial Chemotherapy 20:7-13.

Livermore D M, Yang Y $1987 \beta$-lactamase-lability and inducerpower of newer $\beta$-lactam antibiotics in relation to their activity against $\beta$-lactamase-inducibility mutants of Pseudomonas aeruginosa. Journal of Infectious Diseases 155 : 775 782.

Lowry O H, Rosebrough N J, Farr A L, Randall R J 1951 Protein measurement with the Folin phenol reagent. Journal of Biological Chemistry $193: 265-75$.

O'Callaghan C H, Muggleton P W, Ross G W 1969 Effects of $\beta$ lactamase from Gram-negative organisms on cephalosporins and penicillins. In: Hobby GL (ed) Antimicrobial Agents and Chemotherapy. American Society of Microbiology, Bethesda, MD, pp. 57-63.

Richmond M H, Sykes R B 1973 The $\beta$-lactamases of Gramnegative bacteria and their possible physiological role. Advances in Microbial Physiology 9:31-88.

Sanders C C 1983 Novel resistance selected by the new expanded-spectrum cephalosporins: a concern. Journal of Infectious Diseases 147:585-589.

Sanders C C, Sanders W E 1985 Microbial resistance to newer generation $\beta$-lactam antibiotics: clinical and laboratory implications. Journal of Infectious Diseases 151 : 399-406.

Seeberg A H, Tolxdorff-Neutzling R M, Wiedemann B 1983 Chromosomal $\beta$-lactamases of Enterobacter cloacae are responsible for resistance to third-generation cephalosporins. Antimicrobial Agents and Chemotherapy 23:918-925.

$\mathrm{Vu} \mathrm{H}$, Nikaido H 1985 Role of $\beta$-lactam hydrolysis in the mechanism of resistance of a $\beta$-lactamase-constitutive Enterobactercloacae strain to expanded-spectrum $\beta$-lactams. Antimicrobial Agents and Chemotherapy 27:393-398.

Waley S G 1974 A spectrophotometric assay of $\beta$-lactamase action on penicillins. Biochemical Journal 139:789-790.

Wiedemann B 1986 Genetic and biochemical basis of resistance of enterobacteriaceae to $\beta$-lactam antibiotics. Journal of Antimicrobial Chemotherapy 18 suppl. B:31-38. 